\title{
Calculation of productivity of multi-section trawls for extraction of ferromanganese nodules
}

\author{
Maxim Rakhutin ${ }^{1}$, Alexey Kashirsky ${ }^{2}$, and Yuliya Lagunova $^{3}$ \\ ${ }^{1}$ National Research Technological University “MISiS”, 119049 Moscow, Russia \\ ${ }^{2}$ Ministry of Industry and Trade of the Russian Federation, 125039 Moscow, Russia \\ ${ }^{3}$ Ural State Mining University, 620144 Ekaterinburg, Russia
}

\begin{abstract}
A mathematical model of the operational productivity of trawls for the extraction of ferromanganese nodules from the bottom of the World Ocean is proposed. On the example of the previously proposed cassette trawl, the analysis of the influence of the main factors on the value of operational productivity is carried out.
\end{abstract}

\section{Introduction}

Deposits of the bottom of the oceans are a very promising source of minerals and contain almost their entire spectrum in volumes that in many useful components significantly exceed the reserves of continental land [1].

The most studied are the Pacific nodules from the ore province of Clarion-Clipperton. Deep-water ferromanganese nodules are mainly rounded contraction of black and brownish-black in color with a rough surface. Their average size is $3-8 \mathrm{~cm}$, although there are specimens with a diameter of up to $20 \mathrm{~cm}$ or more [2].

Currently, underwater mining is a very topical issue [3-6].

A wide range of different machines and systems for mining ferromanganese nodules is proposed. All of them can be conditionally divided into several groups, for example, by the type of energy used [7]. Mechanical: multi-bucket and clamshell shells and dredges, scraper-rope installations, self-propelled and trailed scrapers, underwater self-propelled vehicles. Mechanohydraulic: dredger shells, ejector shells and dredges with mechanical cultivators. Hydraulic: ejector shells and dredges with hydraulic cultivators, airlift shells $[8,9,10]$.

\section{Materials and Methods}

The main requirement for equipment for industrial deep-sea mining is its simplicity and reliability. Promising, in our opinion, is the direction of using high-performance trawls for collecting ferromanganese nodules. A cassette trawl design is proposed. An application has been submitted for the construction of a multi-section trawl; developments are being carried out in the field of further improvement of their designs. 
For the convenience of analyzing the production process and improving the accuracy of forecasting the productivity of the complex (vessel, tugboat, multi-section trawl), a model and calculation formula of operational (actual) We capacity are performance.

In this article, the model of operational productivity is considered on the example of a cassette trawl $[11,12]$ shown in Fig. 1. The principle of operation of this trawl is based on the emergence of mesh tanks after they are filled with ferromanganese nodules without lifting the main trawl. Tanks, in the amount of 12 pieces are in a special cassette.

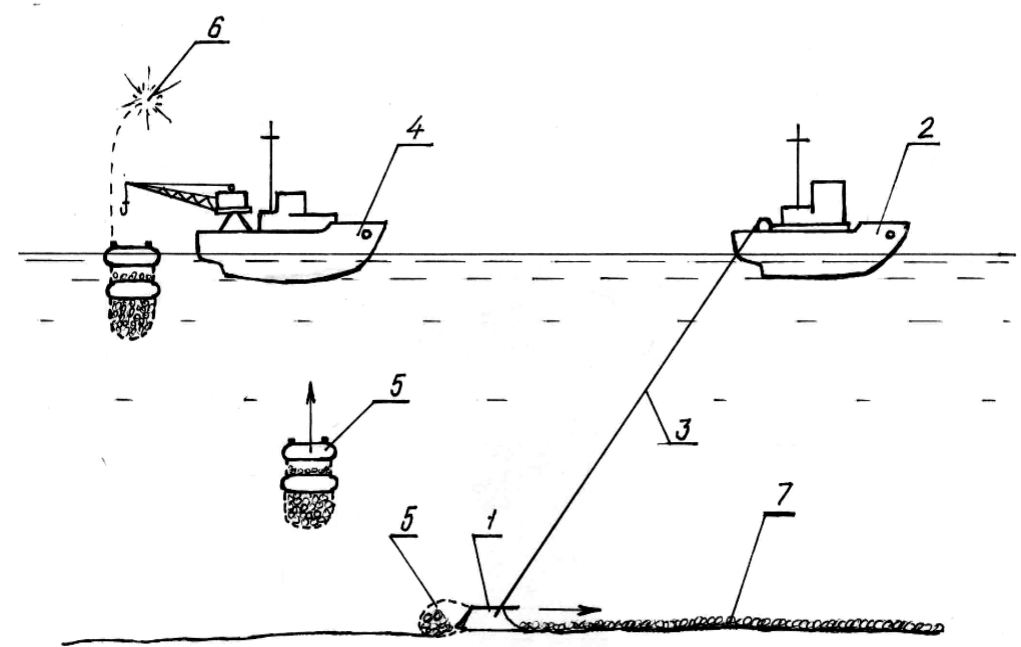

Fig. 1. Schematic diagram of the development of deposits of ferromanganese nodules with help a cassette trawl: 1 - cassette trawl (ladle bucket), 2 - towing vessel, 3 - towing cable, 4 - picking ship, 5 - pop-up mesh tanks, 6 - signaling device, 7 - nodule field.

\section{Results and Discussion}

In the development of models and calculations based on them, by analogy with the processes of mining, it is proposed to consider two types of productivity - technical and operational.

The technical productivity of multi-section trawls is taken equal to the maximum possible productivity in the mining conditions under consideration. In the model of technical productivity, it is proposed to consider the following factors:

- trawl width (entry) Ae, m;

- the density of nodules $q_{d}, \mathrm{t} / \mathrm{m}^{2}$;

- speed of movement (towing) of a trawl $v, \mathrm{~m} / \mathrm{min}$;

- the depth of nodules $H$, m;

- the speed of raising and lowering the trawl $V_{c n}, \mathrm{~m} / \mathrm{min}$, to simplify the model, the ascent and descent speeds are taken equal

- the completeness of the collection of nodules Kc. The coefficient has a range from 0 to 1 , in the absence of losses during the collection of LMF, the proposed coefficient takes the value "1";

- dilution of nodules with adhering sludge $\eta$, it is proposed to determine using the expression: $\eta=0.01 x(100-P \%)$, where $P \%$ is the percentage dilution of nodules with adhering sludge; 
- meteorological conditions are proposed to be considered using the coefficient of "meteorological conditions" $K_{m}$, determined by the ratio of the number of days favorable for mining $N_{b}$ to their total number $N_{o}$.

$$
K_{m}=\frac{N_{b}}{N_{0}}
$$

As the cassette trawl is considered in the example, the following factors must also be considered:

- the duration of the preparation of the cassette trawl on the vessel for work (loading), $\min T_{p}$

- capacity of the tank $Q, \mathrm{t}$;

- the number of mesh containers in the cassette $n$;

- the duration of the separation of the filled mesh and the preparation of the next to work, $\min T_{s}$;

Using the above factors, the model of the value of technical productivity takes the form:

$$
W=A_{\varepsilon} \cdot V^{*} \cdot q_{d} \cdot K_{e} \cdot \eta \cdot K_{m} \cdot \frac{\sum_{i=1}^{n} \frac{Q \cdot \eta}{A_{e} \cdot q_{d^{*}} \cdot K_{e}}}{\sum_{i=1}^{n} \frac{Q \cdot \eta}{A_{e} \cdot q_{d} \cdot V^{*} K_{e}}+\frac{2 H}{V_{c n}}+\sum_{i=1}^{n} T_{s}+T_{p}} \quad t / m i n
$$

In the model of the value of operational (actual) productivity, it is proposed to additionally consider the following factors:

- the reliability of the complex is proposed to be considered through the value of the availability factor $K_{g}$;

- the level of organization of work $T_{o w}, \mathrm{~min} /$ cycle. The level of organization of work is determined through the duration of downtime for organizational reasons in one cycle, for example, the inability to unload pop-up containers

Using the above factors, the model of the value of operational (actual) productivity takes the form:

$$
W_{e}=A_{e} \cdot V \cdot q_{d} \cdot K_{e} \cdot \eta \cdot K_{m} \cdot \frac{\sum_{i=1}^{n} \frac{Q \cdot \eta}{A_{e} \cdot q_{d} \cdot V \cdot K_{e}}}{\frac{1}{K_{g}} \sum_{i=1}^{n} \frac{Q \cdot \eta}{A_{e} \cdot q_{d} \cdot V^{*} \cdot K_{e}}+\frac{2 H}{V_{c n}}+\sum_{i=1}^{n} T_{s}+T_{p}+T_{\text {oV }}}
$$

Let us analyze the influence of the depth of development and the speed of movement of the trawl on technical and operational performance.

Let us analyze the influence of the depth of development and the speed of movement of the trawl, the value of the availability factor on operational productivity.

The initial data for the calculation is presented in Table 1.

Table 1. The source data for the calculation.

\begin{tabular}{|c|c|c|c|c|c|c|c|c|c|c|c|}
\hline $\begin{array}{c}A_{e}, \\
\mathrm{~m}\end{array}$ & $\begin{array}{c}v \\
\mathrm{~m} / \mathrm{min}\end{array}$ & $\begin{array}{c}q_{d}, \\
\mathrm{~kg} / \mathrm{m}^{2}\end{array}$ & $K_{c}$ & $\mathrm{n}$ & $T_{s}, \min$ & $T_{o w}, \min$ & $H, \mathrm{~m}$ & $\eta$ & $V_{c n} \mathrm{~m} / \mathrm{min}$ & $Q, \mathrm{~kg}$ & $K_{g}$ \\
\hline 2 & 30 & 20 & 0.95 & 12 & 1 & 10 & $50-5000$ & 0.9 & $50 ; 100 ; 200$ & 500 & $\begin{array}{c}0.75- \\
0.9 \\
5\end{array}$ \\
\hline
\end{tabular}

The value of $K_{m}$ is accepted in all calculations 0.9 , the duration of downtime for organizational reasons is ten percent of the total duration of work and support operations. 
The dependence of operational productivity on the depth of development and the speed of raising and lowering the trawl are shown in Fig. 2

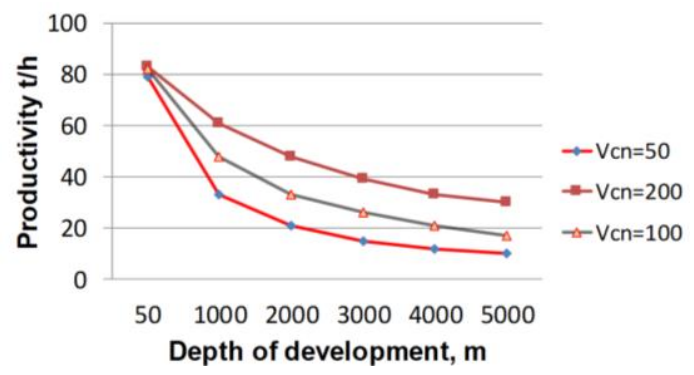

Fig. 2. Dependence of operational productivity on the depth of development and the speed of raising and lowering the trawl.

The dependence of technical productivity on the value of the availability factor $\mathrm{Kg}$ is presented in Fig. 3

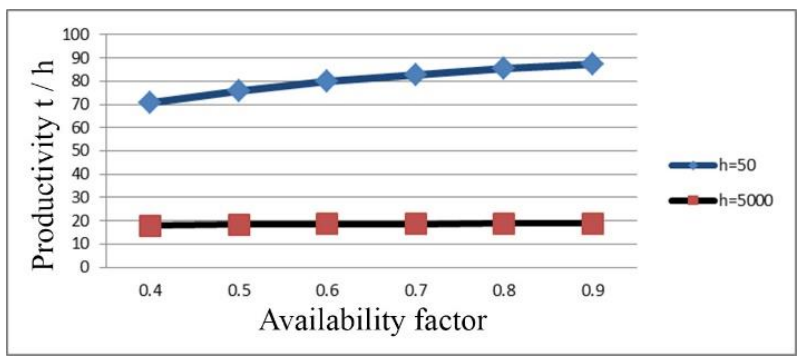

Fig. 3. Dependence of technical productivity on the value of the availability factor.

The graphs show that with increasing depth, the influence of reliability on the performance of the equipment in question decreases sharply. This is because the main factor determining the performance of the equipment in question is the depth of development, the speed of raising and lowering the trawl. The time spent on raising and lowering the trawl with increasing depth begins to significantly exceed the time spent on troubleshooting equipment failures.

The analysis of the obtained models of technical and operational performance allows us to come to the following conclusions, presented below.

\section{Conclusions}

- The most significant factors determining productivity are the depth, speed of raising and lowering the trawl.

- With increasing development depth, productivity decreases in a quadratic manner.

- The width of the trawl, the speed of trawling, the density of nodules does not significantly affect the performance of the trawl.

- The use of multi-section and cassette trawls is promising and will allow for relatively high productivity.

- With increasing depth of development, the impact of equipment reliability on productivity decreases dramatically. 


\section{References}

1. S.I. Andreev, Mineral resources of the oceans: the concept of study and development for the period until 2020, (2007)

2. P.L Bezrukov, Iron Manganese Nodules of the Pacific Ocean, (1976)

3. A.P. Verzhansky, S.I. Andreev, Mining Journal, 3, (2015)

4. V.P. Drobadenko, A.L. Vilmis, O.A. Lukonina, S.V. Markelov, Mining Journal, 11, (2019)

5. M.W. Lodge, K. Segerson, D. Squires, The International Journal of Marine and Coastal Law, 32, 427 (2017)

6. K.V. Nijen, S.V. Passel, D.A. Squires, Marine Policy, 95 (2018)

7. S.L. Serzhan, G.Yu. Vishnyakov, High intellectual technologies in science and education, 96, (2017)

8. D.A. Yungmeister, R.I. Korolev, E.O. Borodkin, S.A. Lavrenko, A.P. Verzhansky, M.Yu. Nasonov, Mining Information and Analytical Bulletin, 5, 3 (2020)

9. Yu.V. Kirichenko, Mining Journal, 1, 84 (2014)

10. V.S. Rogov, V.V. Frolov, N.S. Nikolskaya, A.L. Titov, Mining Journal, 3, 50 (2012)

11. Yu.V. Kirichenko, A.S. Kashirsky, Mining Journal, 12, 56 (2015)

12. A.S. Kashirsky, M.G. Rakhutin, Yu.V. Kirichenko, E.A. Kuzin, Mining Journal, 6, 123 (2019) 